\title{
The role of veterinarians and feed-store vendors in the prescription and use of antibiotics on small dairy farms in rural Peru
}

\author{
L. E. Redding, ${ }^{*} \dagger^{1}$ F. K. Barg, $\ddagger$ G. Smith, ${ }^{*} \dagger$ D. T. Galligan, ${ }^{*}$ M. Z. Levy, $†$ and S. Hennessy† \\ *School of Veterinary Medicine, University of Pennsylvania, Philadelphia 19104 \\ †Center for Clinical Epidemiology and Biostatistics, Perelman School of Medicine, University of Pennsylvania, Philadelphia 19104 \\ †Department of Family Medicine and Community Health, Perelman School of Medicine, University of Pennsylvania, Philadelphia 19104
}

\section{ABSTRACT}

This study aimed to describe and compare the role of veterinarians and feed-store vendors in the use of antibiotics on small dairy farms in Cajamarca, Peru, a major dairy-producing center characterized by small, rural farms with poor, mostly uneducated farmers. We used a purposive sampling strategy to recruit 12 veterinarians into 2 focus group discussions and supplemented these data with 8 semi-structured interviews with feed-store vendors. Participants reported that inappropriate antibiotic usage was widespread among their clients, which may prevent the efficient use of drugs on farms where animal disease can be devastating to the livelihood of the farmer. Participants also identified many barriers to appropriate prescribing and use, including availability of drugs, competition from other prescribers, economic constraints and habits of farmers, and limited farmer knowledge of drugs and disease. Veterinarians expressed mistrust toward nonprofessional prescribers, whereas feed-store vendors felt that veterinarians were important partners in promoting the health of their clients' animals.

Key words: antibiotic use, lower/middle income countries, veterinarian, feed-store vendor

\section{INTRODUCTION}

Dairy production is a rapidly expanding sector of animal agriculture in lower or middle income (LMI) countries, and small farms generally constitute the majority of producers in these countries. These farmers typically have very low educational levels, and their knowledge of appropriate drug use is often limited; therefore, they often rely on prescribers to provide them with instructions for the proper use of veterinary drugs.

The use of antibiotics in livestock has demonstrated benefits, including improved animal health, higher

Received May 19, 2013.

Accepted August 7, 2013.

${ }^{1}$ Corresponding author: lredding@vet.upenn.edu production levels, and the reduction of foodborne pathogens (Mathew et al., 2007). However, the use of antibiotics can result in several problems, including the emergence of antibiotic-resistant bacteria, human and animal illness, economic losses for farmers and dairy processors, and environmental contamination (Gustafson and Bowen, 1997; Barton, 2000; Hamer and Gill, 2002; Gilchrist et al., 2007; Mathew et al., 2007).

The inappropriate use of antibiotics has been defined by the World Health Organization (WHO) as including any of the following: over or under prescribing, inappropriate dosing, incorrect duration of treatment, incorrect choice of drug for the relevant organism, and the unnecessary use of an expensive drug when older, cheaper drugs are available and clinically adequate (WHO, 2001). The inappropriate use of antibiotics in human medicine in LMI countries has been extensively documented (Wolffers, 1987; Nizami et al., 1996; Paredes et al., 1996; Trostle, 1996; Radyowijati and Haak, 2003; Okeke et al., 2005; Kristiansson et al., 2008, 2009; WHO, 2009; Mitema, 2010; Okeke, 2010). However, very little is known of the use of antibiotics in food animals on small farms in LMI countries.

Studies of antibiotic use in human medicine have found that prescribing practices of physicians and pharmacists, especially in LMI countries, are often at the root of inappropriate antibiotic use (Nizami et al., 1996; Paredes et al., 1996; Radyowijati and Haak, 2003; Sahoo, 2008). Very few such studies have examined the role of providers in antibiotic use and misuse in veterinary medicine. It is possible that veterinarians and feed-store vendors (FSV) who sell antibiotics over the counter may similarly inappropriately prescribe antibiotics or may not provide adequate guidance to farmers to ensure the proper use of antibiotics. The role of antibiotic providers in the use of antibiotics in animal agriculture therefore warrants investigation.

Peru is a middle-income country with a large agricultural focus and a livestock industry worth over $\$ 2$ billion annually (FAO, 2009). Cajamarca, a major dairy center, is characterized mostly by small peri-urban and rural farms $(<15$ cows/farm; Garcia and Gomez, 
2006), with 30,000 registered milk producers producing an estimated 307,187 kg of milk/d (Gerz and Boucher, 2006).

In Peru, as in most middle-income countries, antibiotics are used for mostly therapeutic purposes in dairy cattle. These drugs can be obtained and administered several ways: they can be sold, prescribed, or administered by veterinarians, veterinary technicians, or community animal health workers, and they can be sold by FSV (over the counter) and drug promoters and administered by the farmer. There are no enforced limitations on the types of antibiotics that FSV or veterinary professionals can sell or administer; all commonly used antibiotics are available to farmers over the counter without the need for an established veterinary-client relationship or a written prescription from a veterinary practitioner. In this paper, we refer to "prescribing" as the act of selecting an appropriate antibiotic and dosage by a provider for a specific illness experienced by a farmer's animal(s). The goals of the study were as follows: (1) to obtain the perspectives of antibiotic providers on current antibiotic use and its appropriateness by dairy farmers in Cajamarca; (2) to determine which factors influence a provider's prescribing practices; and (3) to compare these 2 aims between veterinarians and FSV.

\section{MATERIALS AND METHODS}

In qualitative studies, participants are purposefully sampled to include "informants with a broad general knowledge of the topic or those who have undergone the experience and whose experience is considered typical" (Morse, 1991). Purposeful sampling yields a wide range of responses but is not intended to represent views in proportion to their numbers in the wider population (as would happen with random sampling). This can be particularly useful to generate hypotheses when little is known about the key variables involved. Veterinarians from a nonprofit organization dedicated to improving farming practices in Cajamarca were recruited to participate in a series of focus group discussions (FGD), a study technique in which a group of relevant participants is convened and asked "focused" questions about a particular topic (Kreuger, 1994). Because it would have been difficult to convene an FGD of FSV, the FSV were individually approached and asked the same "focused" questions in the form of semi-structured questionnaires.

The FGD participants worked daily with dairy farmers in Cajamarca on both a clinical and an advisory or training basis. The FSV worked in agriculture stores, where they sell, among other things, animal drugs over the counter (i.e., without a prescription). The typical clientele of both groups of participants consists of small, poor, rural farmers with 1 to 5 cattle that are housed and grazed on small pastures, manually milked, and produce 5 to $10 \mathrm{~kg}$ of milk daily.

A written discussion guide and questionnaire developed based on a review of the literature and clinical veterinary expertise was used (available online: http:// dx.doi.org/10.3168/jds.2013-7045). It is important to note that although all questions on the guide were asked, the discussion was dynamic and participants often elaborated on a topic at length and were allowed to branch out into other related topics. The FGD and interviews were conducted in Spanish at Foncreagro offices and in feed-stores, respectively, and audio-recorded in July 2012. Approval for this study was obtained from the Institutional Review Board of the University of Pennsylvania (Philadelphia) and from the Comité Ética of the Universidad Peruana Cayetano-Heredia (Lima, Peru).

Interviews were transcribed verbatim by a professional Peruvian transcriber. Transcripts were read in toto by a single investigator to identify key codes (a group of words or statements that relates to the same central meaning) and to develop a coding dictionary using grounded theory; in the grounded theory method, categories are developed from a close reading of the data, content is coded, and category counts are considered as codes are synthesized (Glaser and Strauss, 1967). Transcripts were loaded into NVivo software (version 10.0, 2012; NVivo qualitative data analysis software, QSR International Pty. Ltd., Doncaster, VIC, Australia), which allows text to be coded, sorted, retrieved, and queried across sources (i.e., focus groups, interviews), individual participants and attributes (including sex, profession, and years in the profession). The data were coded using the constant comparative method, which involves the revision of coding as themes emerge from the data and the checking of coding against that of other documents to establish similarities and differences across data sources and participants (Glaser, 1965). Briefly, information pertaining to a particular theme was labeled with a relevant code, and responses could be assigned as many codes as were applicable. For example, if a participant mentioned how economic hardships of a client prohibited them from buying the appropriate amount of an antibiotic, this quote was coded as "inappropriate use of antibiotics," "underdosing," and "economic hardships." Codes were considered important if they were mentioned more than 5 times or discussed by more than 3 participants.

\section{RESULTS}

Six veterinarians participated in each FGD, including 5 men and 1 woman (FGD1) and 4 men and 2 women 
Table 1. Quotes illustrating various topics discussed in focus group discussions (FGD1 and FGD2) with veterinarians and interviews with feedstore vendors (FSV)

\begin{tabular}{|c|c|}
\hline Topic & Relevant quote \\
\hline Appropriate drug for clinical situation & $\begin{array}{l}\text { "What we often see in the field is the misuse of antibiotics. For any disease, people reach for } \\
\text { antibiotics without a proper diagnosis. We also see many cases where an antibiotic is confused with } \\
\text { an antiparasitic drug - in some cases, people think they're dosing [against parasites] but they are in } \\
\text { fact using an antibiotic." (Veterinarian, FGD1) }\end{array}$ \\
\hline Proper dosing & $\begin{array}{l}\text { "If, for example, we tell [a farmer] that they have to dose the animal with } 1 \mathrm{~mL} / \mathrm{kg} \text {, the farmer } \\
\text { doesn't do so; some apply less, others apply more, saying "More is better," although not always. In } \\
\text { the field, people often do not pay attention to indications [for the drug]." (Veterinarian, FGD2) }\end{array}$ \\
\hline Avoidance of residues & $\begin{array}{l}\text { "Most producers know that milk with residues should not be sent [to the milk company]. If the milk } \\
\text { company doesn't say anything to them and we tell them they shouldn't send milk with residues, } \\
\text { they send it anyway." (Veterinarian, FGD1) }\end{array}$ \\
\hline \multicolumn{2}{|l|}{ Barriers to proper prescribing } \\
\hline Perception of clients' abilities & $\begin{array}{l}\text { "The problem here is that farmers have a very limited education. Most haven't even been to primary } \\
\text { school. Even when they receive training [in proper drug usage], they get confused because each } \\
\text { veterinarian from each laboratory has his own criteria, so the farmers easily get confused." (FSV) }\end{array}$ \\
\hline Clients' economic means & $\begin{array}{l}\text { "More than anything, I always say that the market of small producers has a lot to do with } \\
\text { price. [Farmers] are always looking for the cheapest product. [...] For example, penicillin is } \\
\text { most expensive, oxytetracyclines are cheapest, and there are a large number of products of later } \\
\text { generations which are much more expensive - impossible to use them in rural areas." (FSV) }\end{array}$ \\
\hline Drug inventory & $\begin{array}{l}\text { "It was very difficult to obtain penicillins on the market, which is why I say the market was not } \\
\text { providing them. Oxytetracycline was used so often, and a study showed that Staph. aureus was } \\
\text { highly resistant to antibiotics. Animals responded well to penicillin, but it was hard to find that } \\
\text { drug." (Veterinarian, FGD1) }\end{array}$ \\
\hline
\end{tabular}

(FGD2). Eight FSV, all men, were interviewed. Veterinarians had been practicing for an average of $6.8 \mathrm{yr}$ (FGD1) and $5.5 \mathrm{yr}$ (FGD2), and FSV had worked for an average of $6.2 \mathrm{yr}$ in their stores. Thematic saturation, or the replication of data collected from different participants that are similar and fit within the same category (Meadows and Morse, 2001), was achieved with these 2 FGD and 8 FSV interviews.

Veterinarians identified 4 main criteria for proper antibiotic use (Table 1). First, antibiotics should be used in the correct clinical situation; that is, for a bacterial infection only. Conversely, other drugs - especially antiparasitics - should not be used in the place of an antibiotic when an antibiotic is called for. Second, the recommended dosage should be followed, both in terms of quantity $(\mathrm{mg} / \mathrm{kg})$ and duration of treatment. Third, microbiological tests should be used to identify the pathogen and its resistance profile. Fourth, drug withdrawal times should be respected to avoid the occurrence of antibiotic residues in milk. All veterinarians agreed that farmers generally failed to adhere to all 4 criteria. For FSV, the correct use of antibiotics consisted of specifically not confusing an antibiotic with an antiparasitic drug and using the proper dose $(\mathrm{mg} / \mathrm{kg})$. Three of the $8 \mathrm{FSV}$ thought that antibiotics were more or less appropriately used among their clients, whereas
5 thought that antibiotic use was inappropriate and indiscriminate.

Veterinarians expressed that, because they are always able to examine the affected animal and make an informed clinical decision, their prescribing practices were generally appropriate. The FSV mentioned that, because they were unable to observe the animal and had to depend on often vague descriptions of symptoms from owners, they felt less able to ensure the proper use of antibiotics than veterinarians; furthermore, all of the FSV reported that at least half of their clients who purchased antibiotics requested a specific antibiotic instead of asking the vendor for guidance. Both types of prescribers acknowledged that they sometimes felt obliged to prescribe antibiotics inappropriately. The most frequently cited factors associated with inappropriate prescribing are listed in Table 2 and illustrated in a conceptual framework in Figure 1. Relevant quotes detailing barriers to prescribing are shown in Table 1.

The clinical situation was the most important factor determining a prescriber's choice of antibiotic and decision to prescribe. Veterinarians asserted that a thorough examination of the animal and a detailed history were necessary before prescribing an antibiotic, and broad-spectrum antibiotics were generally the drugs of choice. Seven of the 8 FSV reported trying to obtain 
Table 2. Frequency of discussion of essential points found to significantly influence antibiotic prescribing practices of veterinarians and feedstore vendors (FSV)

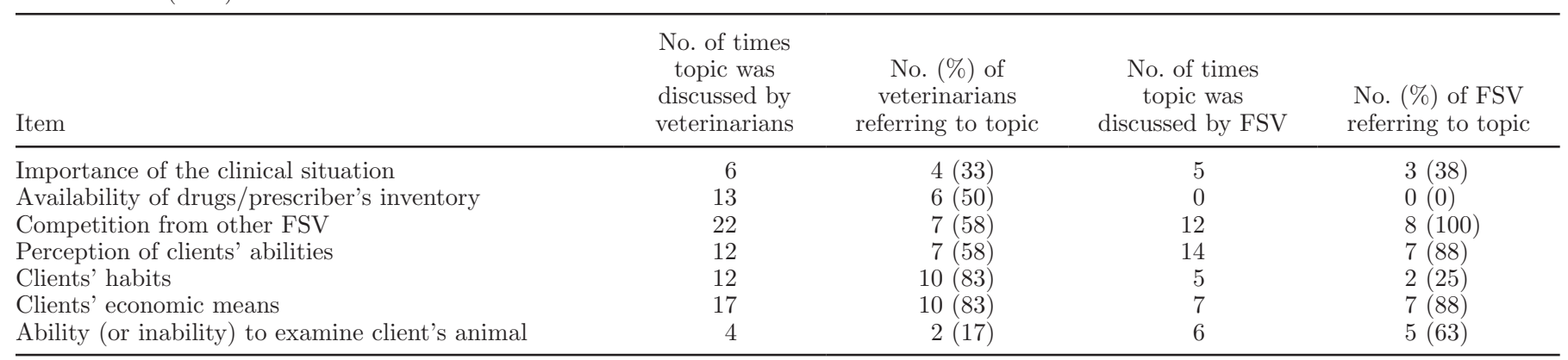

some sort of history of the sick animal before recommending an antibiotic.

According to the veterinarians, oxytetracyclines are the most commonly prescribed antibiotics in Cajamarca, and over-reliance on this antibiotic was due, in large part, to the widespread availability of this drug and the relative paucity of other drugs on the market in Cajamarca (Table 1). Veterinarians reported that a revolving selection of antibiotics tended to be available in feed stores, with different names, packaging, and active ingredients, thus complicating the consistent use of antibiotics by both farmers (who often rely on visual memory of a drug) and veterinarians (who were not always able to subsequently locate a product they had used in the past). None of the FSV believed that inventory in their own store was a problem, but one of the FSV mentioned that adulterated or counterfeit drugs were widely sold on the market and that many farmers were often sold inadequate products by other vendors.

Veterinarians mentioned that the low education level of their clients and their limited ability to understand drug indications, active ingredients, or disease pathologies sometimes influenced their prescribing practices: they often felt unable to explain why a certain drug is needed for a certain period of time and at a certain

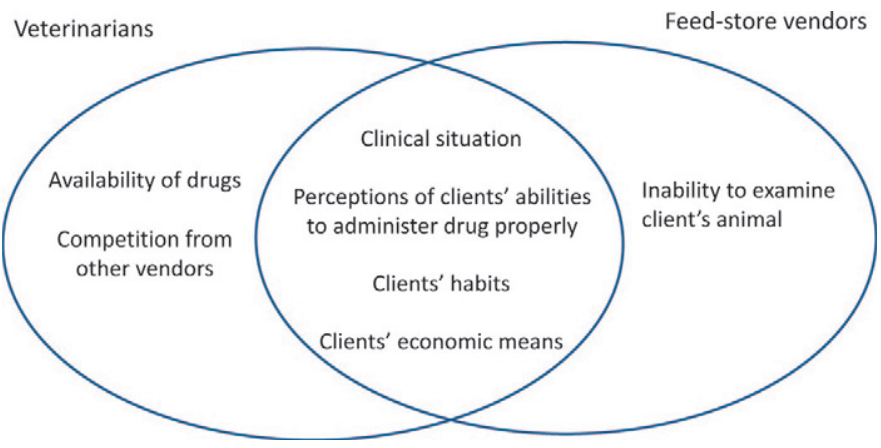

Figure 1. Conceptual framework describing the factors influencing the prescribing practices of animal health professionals. Color version available in the online PDF. dose, and they maintained very low expectations that their instructions would actually be followed by farmers. In contrast, half of the FSV, while acknowledging the limited ability of clients to understand drug indications and disease, believed that the instructions they gave their clients when dispensing antibiotics were adequately followed.

Major determinants of the type and quantity of antibiotic prescribed by both veterinarians and FSV involved clients' expectations or habits and needs. First, farmers acquire customs from their family, friends, and neighbors, often leading them to purchase the same products, even if their efficacy is limited. Second, financial constraints were a major limiting factor in the ability to effectively treat animals. The majority of farmers in the area are quite poor (earning less than $\$ 1.25$ a day), and the sale of milk constitutes their sole source of income. Both veterinarians and vendors admitted to sometimes prescribing antibiotics they knew were not going to be effective because farmers could not afford anything else.

Veterinarians felt pressure to compete with other prescribers (e.g., FSV and drug promoters) in providing drugs and services to farmers. They felt that they were at a disadvantage compared with nonprofessional prescribers for whom economic motivation was a high priority and a lack of clinical knowledge often resulted in inappropriate prescribing practices. Veterinarians also expressed concern that farmers were more likely to buy their drugs from nonprofessional prescribers who were more likely to "accommodate" their preferences than a veterinarian, and that veterinary care was only sought in complicated clinical situations that could not easily be handled by a nonprofessional. Overall, veterinarians were mistrustful of nonprofessional prescribers. In contrast, all FSV mentioned that, especially if a case was complicated or unclear, they would defer to a veterinarian or encourage clients to seek veterinary help. Overall, FSV appeared to view veterinarians as collaborators and valuable sources of clinical expertise for treating clients' animals rather than as competition. 


\section{DISCUSSION}

Overall, prescribers felt that antibiotics were not often used appropriately for a variety of reasons and that there was often little they could do to improve antibiotic use among their clients. Training or educating farmers on the appropriate use of antibiotics was attempted by both veterinarians and FSV but was not always successful, especially because farmers sometimes received conflicting advice and information from a variety of prescribers. Furthermore, the appropriate use of antibiotics sometimes depended on other parties, such as milk companies that readily purchased milk with antibiotic residues.

Some of the drivers behind antibiotic prescribing practices in veterinarians and FSV are similar to those encountered in human medicine in other LMI countries. In Sri Lanka, for example, Wolffers (1987) found that no information on proper drug use was provided with the sale of antibiotics and that pharmacy personnel had no pharmaceutical qualifications and knew little about the drugs they were dispensing. In Peru, Paredes et al. (1996) found that the practices of antibiotic prescriptions by physicians were more related to social expectations and perceptions of the physician's role than to medical or scientific reasoning. Radyowijati and Haak (2003) found that a lack of appropriate knowledge on the part of providers, lack of trust in delayed laboratory results, unstable or inadequate drug supply, economic incentives, and the desire to meet patient demand led to inappropriate antibiotic prescribing by physicians and pharmacists. Similarly, some of the barriers to appropriate prescribing were found to be similar in human medicine: Haak (1988) found that patients in Brazil based their decisions to buy antibiotics on advice from friends and relatives, who, in turn, were strongly influenced by previous medical prescriptions and their own habits and customs; Sahoo (2008) found that incomplete courses of antibiotics in India due to patient poverty were common. Although we noted significant overlap in the obstacles to appropriate prescribing reported by veterinarians and FSV, some differences were noted, including the limited availability of certain drugs and competition from nonprofessional prescribers (in the case of the veterinarians) and the inability to examine the animal (in the case of FSV).

Veterinarians expressed skepticism toward and mistrust of other nonprofessional prescribers (FSV, drug promoters, and technicians). The FSV viewed veterinarians as important collaborators in improving animal health in Cajamarca. Improved relations and interactions between these groups of prescribers would likely be useful in dispelling misconceptions and could contribute to the promotion of the improved use of antibiotics. In particular, the training of FSV by veterinarians in the appropriate use of antibiotics and the development of specific guidelines for appropriate prescribing and training of farmers could be useful.

Several possible limitations of the study are worth mentioning. As in many qualitative studies, potential information bias and limited generalizability are important limitations. The participants may have been motivated by social desirability and therefore may not have been entirely forthright in their responses; however, because the focus group methodology is one of the best ways to promote candid discussion and peer interaction (Kreuger, 1994), information bias may have been mitigated.

The generalizability of the results of this study may be limited, as veterinarians and FSV were from a single geographic region. Furthermore, the veterinarians were employees of a nonprofit organization that aims to improve farming practices on small dairy farms; participants may therefore have been especially attuned to concepts of best-farming practices and motivated by outcomes related to sustainable farming practices rather than strictly to animal health. The number of FSV interviewed, although appearing small, achieved thematic saturation, or the replication of data collected from different participants that are similar and fit within the same category (Meadows and Morse, 2001). Overall, a wide range of topics was discussed in the FGD and interviews, and many overlapping themes were found in both groups; it is likely that aspects of the discussion are generalizable to the use of antibiotics in dairy cattle across Peru and throughout LMI countries in Latin America.

\section{ACKNOWLEDGMENTS}

The authors acknowledge the Institute for Biotechnology Futures and the Sigma Delta Epsilon/Graduate Women in Science for their contributions towards the funding of this research project. Leaders of Foncreagro (Cajamarca, Peru), and Sergio Gonzalez Nuñez in particular, were instrumental in recruiting participants, and the authors are grateful for their assistance. The authors declare that they have no conflicts of interest.

\section{REFERENCES}

Barton, M. D. 2000. Antibiotic use in animal feed and its impact on human health. Nutr. Res. Rev. 13:279-299.

FAO. 2009. FAO Stat. Accessed August 2013. http://faostat3.fao.org/ faostat-gateway/go/to/download/C/CL/E.

Garcia, O., and C. Gomez. 2006. The economics of milk production in Cajamarca, Peru, with particular emphasis on small-scale producers. Pro-Poor Livestock Policy Initiative (PPLPI)/FAO: A Living From Livestock. PPLPI Working Paper No. 34. Food and Agriculture Organization of the United Nations, Rome, Italy. 
Gerz, A., and F. Boucher. 2006. Mantecoso cheese in Peru: Organizing to conquer the national market. Pages 41-51 in Origin-Based Products: Lessons for Pro-Poor Market Development. Royal Tropical Institute, CIRAD (Centre de coopération internationale en recherche agronomique pour le développement), France.

Gilchrist, M. J., C. Greko, D. B. Wallinga, G. W. Beran, D. G. Riley, and P. S. Thorne. 2007. The potential role of concentrated animal feeding operations in infectious disease epidemics and antibiotic resistance. Environ. Health Perspect. 115:313-316.

Glaser, B. G. 1965. The constant comparative method of qualitative analysis. Soc. Probl. 12:436-445.

Glaser, B. G., and A. L. Strauss. 1967. The Discovery of Grounded Theory: Strategies for Qualitative Research. Aldine Publishers, Chicago, IL.

Gustafson, R. H., and R. E. Bowen. 1997. Antibiotic use in animal agriculture. J. Appl. Microbiol. 83:531-541.

Haak, H. 1988. Pharmaceuticals in two Brazilian villages: Lay practices and perceptions. Soc. Sci. Med. 27:1415-1427.

Hamer, D. H., and C. J. Gill. 2002. From the farm to the kitchen table: The negative impact of antimicrobial use in animals on humans. Nutr. Rev. 60:261-264.

Kreuger, R. 1994. Focus Groups: A Practical Guide for Applied Research. 2nd ed. Sage Publications Newbury Park, CA.

Kristiansson, C., M. Grape, E. Gotuzzo, F. Samalvides, J. Chauca, M. Larsson, A. Bartoloni, L. Pallecchi, G. Kronvall, and M. Petzold. 2009. Socioeconomic factors and antibiotic use in relation to antimicrobial resistance in the Amazonian area of Peru. Scand. J. Infect. Dis. 41:303-312.

Kristiansson, C., M. Reilly, E. Gotuzzo, H. Rodriguez, A. Bartoloni, A. Thorson, T. Falkenberg, F. Bartalesi, G. Tomson, and M. Larsson. 2008. Antibiotic use and health-seeking behaviour in an underprivileged area of Peru. Trop. Med. Int. Health 13:434-441.

Mathew, A. G., R. Cissell, and S. Liamthong. 2007. Antibiotic resistance in bacteria associated with food animals: A United States perspective of livestock production. Foodborne Pathog. Dis. 4:115-133.

Meadows, L., and J. Morse. 2001. Constructing evidence within the qualitative project. Pages 187-200 in The Nature of Qualitative Evidence. J. Morse, J. Swanson, and A. Kuzel, ed. Sage Publications, Thousand Oaks, CA.

Mitema, E. S. 2010. The role of unregulated sale and dispensing of antimicrobial agents on the development of antimicrobial resistance in developing countries. Pages 430-411 in Antimicrobial Re- sistance in Developing Countries. A. J. Sosa, D. K. Byarugaba, C F. Amábile-Cuevas, and P.-R.Hsueh, S. Katiuki, and I. N. Okeke, ed. Springer, Dordrecht, the Netherlands.

Morse, J. 1991. Strategies for sampling. Pages 127-145 in Qualitative Nursing Research: A Contemporary Dialogue. Sage, Newbury Park, CA.

Nizami, S. Q., I. A. Khan, and Z. A. Bhutta. 1996. Drug prescribing practices of general practitioners and paediatricians for childhood diarrhoea in Karachi, Pakistan. Soc. Sci. Med. 42:1133-1139.

Okeke, I. N. 2010. Poverty and root cause of resistance in developing countries. Pages 27-35 in Antimicrobial Resistance in Developing Countries. A. J. Sosa, D. K. Byarugaba, C. F. Amábile-Cuevas, and P.-R.Hsueh, S. Katiuki, and I. N. Okeke, ed. Springer, Dordrecht, the Netherlands.

Okeke, I. N., R. Laxminarayan, Z. A. Bhutta, A. G. Duse, P. Jenkins, T. F. O'Brien, A. Pablos-Mendez, and K. P. Klugman. 2005. Antimicrobial resistance in developing countries. Part I: Recent trends and current status. Lancet Infect. Dis. 5:481-493.

Paredes, P., M. de la Pena, E. Flores-Guerra, J. Diaz, and J. Trostle. 1996. Factors influencing physicians' prescribing behaviour in the treatment of childhood diarrhoea: Knowledge may not be the clue. Soc. Sci. Med. 42:1141-1153.

Radyowijati, A., and H. Haak. 2003. Improving antibiotic use in lowincome countries: An overview of evidence on determinants. Soc Sci. Med. 57:733-744.

Sahoo, K. C. 2008. Antibiotic use, environment and antibiotic resistance: A qualitative study among human and veterinary health care professionals in Orissa, India. Applied Ecology, School of Business and Engineering, University of Halmstad, Sweden.

Trostle, J. 1996. Inappropriate distribution of medicines by professionals in developing countries. Soc. Sci. Med. 42:1117-1120.

WHO (World Health Organization). 2001. Monitoring antimicrobial usage in food animals for the protection of human health. Report of a WHO consultation, Oslo, Norway, September 2001. World Health Organization Department of Communicable Disease, Surveillance and Response. Accessed August 2013. http://whqlibdoc. who.int/hq/2002/WHO_CDS_CSR_EPH_2002.11.pdf.

WHO (World Health Organization). 2009. Medicines use in primary care in developing and transitional countries. Fact Book summarizing results from studies reported between 1990 and 2006. WHO, Geneva, Switzerland.

Wolffers, I. 1987. Drug information and sale practices in some pharmacies of Colombo, Sri Lanka. Soc. Sci. Med. 25:319-321. 